This is the peer reviewed version of the following article: Fellin, L. C., Callaghan, J. E., Alexander, J. H., Mavrou, S. and Harrison-Breed, C. (2019), Child's Play? Children and Young People's Resistances to Domestic Violence and Abuse. Child Soc, 33: 126-141, which has been published in final form at https://doi.org/10.1111/chso.12302. This article may be used for non-commercial purposes in accordance with Wiley Terms and Conditions for self-archiving.

Title: Child's Play? Children and young people's resistances to domestic violence and abuse Published in Childhood and Society

Authors:

Lisa C. Fellin, University of East London

Jane E.M. Callaghan, Centre for Child Wellbeing and Protection, University of Stirling

Joanne H. Alexander, University of Northampton

Stavroula Mavrou, Aristotle University Thessaloniki

Claire Harrison-Breed, University of Northampton

Running Title: Play as resistance to domestic violence

Corresponding Author Jane.E.M. Callaghan, Centre for Child Wellbeing and Protection, University of Stirling, Stirling, FK9 4LA 


\section{Child's Play? Children and young people's resistances to domestic violence and abuse}

Abstract

Children and young people's (CYP) space to play can be constrained in families affected by domestic violence and abuse, potentially impacting their development. Play also has the potential to strengthen CYP's capacity to resist controlling and abusive dynamics in the family. Interviews were conducted with 107 children and young people aged 8-18, and were analysed using interpretive interactionism. Three themes relevant to children's experiences of play were identified: Play and Coercive Control; Play Re-makes the World; and Play and Relationality. This article highlights the potential for play to enable children to retain a sense of relational connectedness and agency, despite violence and control; we argue for more opportunities for children to play away from the gaze of adults and advocate for more dedicated services for families who experience DVA. 
Children and young people (CYP) who experience domestic violence and abuse (DVA) face a range of psychosocial and developmental challenges (Wood and Sommers, 2011). DVA and coercive control (Stark, 2007) are not limited to the intimate dyad in which overt violence occurs; violence and coercive behaviour pervade familial relationships and have significant implications for children's wellbeing and development (Callaghan, Alexander, Sixsmith, et al., 2016; Katz, 2016). Children's capacity for play is one arena that is challenged by DVA; children who have experienced it are less likely to engage in pretend and imitative play (Valentino et al., 2006) and more likely to play repetitively (Vetere and Cooper, 2017). However, play and playfulness also has the potential to strengthen CYP's resilience (Fearn and Howard, 2012; Tomkin, 2014), supporting their capacity to cope with and resist the controlling and abusive dynamics in the family, and to recover after abuse. In their review study, Capurso and Pazzagli (2016) suggested that cognitive emphasis in resilience research underestimates the importance of play, and argue for a focus on the experience, meaning and complexity of children and young people's playfulness.

Parental play is a predictor of the quality and creativity of children's play (Keren et al., 2005). Early parent-infant play experiences are co-creative, and these relational interactions are important for children's future healthy development (Sossin and Cohen, 2011). Most research focuses on motherchild interactions and suggests that these are negatively impacted by maternal mental health and coping (Callaghan, 2015; Katz, 2015), which in turn is seen as impacting play development. (It should be noted that there is generally a lack of research on domestic abuse in families that are not heterosexual.) Maternal post-traumatic stress, and mothers' length of exposure to DVA are seen as mediating the impact of violence on play development (Keren et al., 2005; Levendosky \& GrahamBermann, 2000a; Levendosky et al., 2003; Levendosky et al., 2006). For instance, Waldman-Devi et al (2015), using 15 minute long observations of mother and child play in a laboratory, correlated the coded observations with measures of maternal post-traumatic stress, and concluded that mothers 
who did not meet the criteria for PTSD "had better interactions with more playful children" (Waldman Devi et al, 2015, p. 89). This kind of research positions mothers as responsible for their children's wellbeing, diverting attention away from the impact of (predominantly) male violence to maternal mental health (Callaghan, 2015). Further, in measuring play in this reified and artificial way, this research underestimates the relational and spatial context in which play is enacted, the interactional function of play, and children's own capacity to play. In a manner quite typical of mainstream developmental research this research positions play (and parenting more generally) as something done or facilitated to children, rather than something children engage in both individually and interactionally (Burman, 2017; Callaghan, Fellin, et al., 2017).

In clinical literature on children's experiences of violence and trauma, much focus has rested on traumatic re-enactment in play, or 'post-traumatic play' (Terr, 1981; Glodich and Allen, 1998; Gil, 2013, 2017). Post-traumatic play involves some re-enactment of the child's traumatic experience, and is characterised by a sense of compulsion and repetition, concreteness, with a quality of unconscious drivenness, earnestness, lack of joy and morbidity (Lubit et al., 2002; Gil, 2013); Gil $(2013,2017)$ differentiates between toxic post-traumatic play, which is retraumatising and requires intervention, and a more positive and self-therapeutic one, the dynamic type. However, diagnostic systems position the 'acting out' or repetition of traumatic experiences in play as a symptom of posttraumatic stress (Scheeringa et al., 2012; American Psychiatric Association, 2013; Friedman, 2014; Sachser and Goldbeck, 2016). The conceptualisation, originating from psychodynamic theories of trauma (e.g. Pynoos and Eth, 1985) has remained popular and largely uncontested in clinical practice, despite relatively little empirical support for the concept (Chazan and Cohen, 2010). Children who experience DVA can find it difficult to articulate their experiences, because of the pervasiveness of family secrets or fears about the repercussions of disclosure (Callaghan, Alexander, et al., 2017; Vetere and Cooper, 2017). Despite these limitations, most children do find ways of expressing their experiences, and play is one way they can tell their stories (Callaghan, Alexander, et 
al., 2017; Gil, 2017; Överlien, 2017). Some research suggests that children's play after abuse tend to take one of two forms - either chaotic and frightening, disorganised and uncontrolled, or inhibited a kind of absence of play (Georgsson, Almqvist and Broberg, 2011). However, we argue here that this underestimates children's capacity to story-making and for creating meaning, particularly in the stories they tell through and about play. Such play is not just a 'symptom' of trauma, it also offers significant insight into the experience of traumatic events, and the meaning these hold in the child's life (Almqvist and Broberg, 1997). Cohen et al (2010) completed play observations with a small sample of children who had experienced war related trauma, and compared this to their reported symptoms of PTSD. They found that children who engaged in mostly negative play, characterised by negative emotional expression and aggressive or morbid acting out, tended to have higher rates of post traumatic symptomatology. Play that incorporated re-enactment and self-soothing, in contrast was associated with fewer trauma symptoms. This is consistent with other clinical and research contributions highlighting how play is not merely symptomatic, but also contains elements of the child's capacity to self-sooth and to self- heal (Gil, 2017; Schaefer \& Drewes, 2013). It enables CYP to process and make sense of their experiencing, and includes opportunities to problem-solve and restore a sense of mastery (Goodyear-Brown, 2009).

CYP's maturity and developmental processes play a role in the expression of post-traumatic stress, and it is suggested that post-traumatic play is more common in younger children of pre-school and primary school age, giving way to other forms of traumatic re-enactment (like self-harm, sexual acting out and risk taking) in adolescence (Tedeschi and Billick, 2017). However, in this article we are not focused on the developmental processes of children's post-traumatic play, but in its meaning in the context of their lives, as they navigate families characterised by violence, coercion and manipulation. An exclusive focus on developmental stages may risk an adultist perspective that obscures the contextual locatedness of children's play, and its meaning in the contexts of children's 
own lives, relationships and emotional experiences (James, Jenks and Prout, 1998; Punch, 2000; Skelton, 2009; James and Prout, 2015; Burman, 2017). Clearly from children's own perspective, play is not a developmental achievement, but something they do: they play to communicate, to have fun and to be. There is a significant body of research and literature that focuses on the healing power of play and its invaluable therapeutic applications. In this article, we are interested in CYP's experience of their own play and playfulness, exploring how they describe playing as a means of coping, of retaining a sense of personhood and agency despite abuse, and of resisting dominance and control.

Whilst children's capacity to engage in play is challenged by DVA, play is also a possible arena for meaning making, catharsis, escapism, support and intervention for CYP who have experienced DVA. Play supports healthy psychosocial and cognitive development, and has expressive and cathartic potential. In her work with children living in domestic violence shelters, $\varnothing$ verlien (2011) found that opportunity to play was a valued element of refuge stay, offering children access to space, material, and the freedom to play alone and with others. Katz (2015) identified learning to play together as one way in which mothers and children supported each other in recovery.

Professional therapeutic spaces are one crucial arena in which children's capacity for creative and healing play can be supported (Gil, 2013, 2017); simultaneously, it is important to consider too how children experience play in the everyday, unmediated by adult meaning making. Trauma is not an inevitable outcome of DVA, and many CYP do not access therapeutic support, so it is important to consider other aspects of recovery in order to better support CYP. Our aim in this article is to explore meaning of play in children's lives, in a way that moves beyond the construct of posttraumatic play and enables us to consider children's capacity for agency and for recovery after DVA. We want to consider how children might draw on their capacity for play to retain a sense of personhood, relationality and creative competence, outside the pathologizing discourses of the 
clinic. This is not to deny the negative impact of abuse, or to suggest that children harmed by DVA can somehow 'heal themselves' simply by playing. Rather our intention is to explore additional possible narratives for understanding the intrinsic functions of play.

In a previous paper (Callaghan, Alexander and Fellin, 2016), we explored Scarry's (1985) claim that the pain associated with controlling and systematic violence 'unmakes the world'. In this paper, we consider how play might function as part of CYP's repertoire to cope with and resist DVA. The dominant academic and practitioner account of play largely rests on the notion of it as a developmental necessity and achievement, as something children must do to become adults (Burman, 2017), or else positions play as something 'natural' to children that is damaged and that becomes arrested when children experience trauma or hardship. In contrast, we do not see play only as a developmental achievement or necessity, or as related to stages of children's lives. As Punch (2000) and Burman (2017) suggest, these assumptions about play function to normalise a particular form of privileged, minority childhood (that of the non-working, free to play, middle class western child), neglecting cultural differences (Gil, 2017) as well as diverse life experiences. Our account of children's play in contexts where DVA has occurred resists both the naturalisation of 'normal play development' and the pathologisation of 'post-traumatic play'. Our aim is to explore CYP's accounts of play, and how they understand its function in their experience of living with DVA. Our intention is to consider the place of play in the context of the child's life, as they make meaning of it, a neglected area in previous literature on children's responses to DVA. Play is an embodied, relational and spatially located practice, that on the one hand simply is, for children (resisting the meanings that adults seek to impose on it), and on the other hand is meaningful, communicative, and emotional activity (Marshall, 2016). We explore play "at the intersection of being and becoming" (Harker, 2005, p.58) and resist the imposition of hegemonic adult meanings and practice (Punch, 2000). Our article contributes to the understanding of play as potentially agentic and 
resistant, enabling children to retain a sense of self in the face of coercive and abusive family relationships.

\section{Method}

This paper addresses one theme that emerged from a large four nation European study focused on CYP's capacity for agency in contexts of DVA and recovery. This work is located within a feminist and interpretive interactionist paradigm (Denzin, 2001; Smith, 2005), which assumes that personal 'troubles' are also social and political ones (Thompson, Rickett and Day, 2018). Denzin's approach assumes that our sense of self is narratively constituted, at the intersection of the personal and the political. We adopted a social constructionist lens to consider how personal experiences (in this instance, DVA and coping) are constituted within social, political, and material spaces and practices. Play emerged as one key theme in our broader analysis of children's interviews about coping with the experience of DVA. Our approach enabled us to explore how children understand and experience play and playfulness, whilst also making sense of how that experience is located within a socially constituted notion of childhood, of family and of DVA. The analysis is informed by the understanding that children's play is embodied, relational and spatially located, and uses inductive processes to build an understanding of how children understand the role of play in their experience of coping with DVA.

107 CYP from four countries (England, Greece, Italy and Spain) were recruited through domestic violence services and shelters and interviewed to explore how they managed and coped with their experiences of DVA. All came from families where DVA had occurred, and most came from a context where professionals working with them had identified the father or step father as the main perpetrator.

The research team was sensitive to the ethical complexity of this work, and processes were preagreed to manage ethical concerns and safeguarding issues that were anticipated to arise. The 
project received ethical approval by the lead organisation (UoN) and we ensured it was consistent with European commission ethical guidelines (for the FP7 framework). All partners agreed to adhere to those ethical practices. Our guiding ethical policy involved balancing the rights of children to be heard on matters that affect them and their rights to protection from harm (Eriksson and Näsman, 2012; Morris, Hegarty and Humphreys, 2012), including CYPs' perceived vulnerability, and the potential risks associated with the disclosure of family 'secrets'(Callaghan, Alexander, et al., 2017). We were committed to finding safe ways to facilitate CYP voicing their experiences (Alderson and Morrow, 2004; Skansvors, 2009). Written informed consent was secured if CYP were legally able to give it. If not, assent was sought from children, and consent from parents or legal carers. Participants were fully informed about the nature of the research, and we explained how interview data would be used, the protections afforded by confidentiality, and the circumstances under which confidentiality would have to be breached. CYP were only included in the study if a professional working with the family judged their circumstances to be safe. After each interview, researchers checked with CYP how they had experienced the interview, and if there were any wellbeing concerns, they were referred to specialist support.

In all four countries, semi-structured interviews were based on an agreed interview schedule, that was used flexibly and adapted to the needs of the CYP and the context. We also used creative methods like photo (Bridger, 2013) and graphic elicitation to support the interview, when CYP wanted to use them to express their lived experience. Interviews were conducted in the main language of the country in which they were located (English, Greek, Castilian and Italian), and were audio recorded and transcribed in full. Translations were completed by a bilingual member of the research team, and were cross-checked by a second member. Interviews lasted 24-83 minutes. Interview transcripts were analysed using Interpretive Interactionism, an approach that focuses on lived experience as it is constituted in social and institutional contexts. Each transcript was coded, (what Denzin terms "bracketing the phenomenon"): researchers focused on participants' words and 
expressions as they are in the text of the interview, "cut loose" (Denzin 2001, p. 154) from the researchers' preconceptions, to identify key features and structures of experiences CYP narrated. Bracketed codes were refined by comparison within and across transcripts, exploring patterns in the interviews, classifying and ordering them to produce themes (the "construction" phase). Themes were built to consider commonalities and variability across the interviews, attending to points of intersection between the CYP's narratives and their relational and social context ("contextualisation"). We attended to the CYP's articulated experience, and its intersections with familial relationships, the institution of the family itself, and the social and political construction of DVA as phenomenon. In practical terms the interviews were coded independently by two researchers, who compared coding, discussed points of difference, and refined the coding system. Coding was completed in each country, before being synthesised at a closing workshop in which the main emergent themes from the project were agreed.

Interviewers maintained reflexive records throughout the project. The research was challenging for many of us, as many of the interviews were poignant and difficult to process emotionally. Researchers worked in small teams in each country, enabling discussion and debriefing when needed. In addition, the researchers retained an inter-country network, enabled by regular virtual meetings, to support each other, as well as to enable a robust and coherent approach to the research itself. Politically our stance focused on the importance of enabling a space in which CYP could articulate their experiences of coping with DVA, and as such we often became frustrated with the gatekeeping practices of professionals whose concerns about the potential vulnerability of CYP and risk of re-traumatisation was frequently decided without consultation with the CYP themselves. This highlights the complexity of working ethically with CYP who have experienced violence and other traumatising events, and particularly the difficulties of balancing their right to give voice to their experiences with their right to protection from harm. 


\section{Analysis}

Play emerged as a significant aspect of the experiences of most of the CYP we interviewed. Three intersecting themes emerged from CYP accounts of play as illustrated also by their photo voices. In the first, play and coercive control, we explore how children's ability to play was constrained, and at times deliberately controlled by the abusive adult. However, in the second theme play re-makes the world, we highlight CYP's accounts of the ways that play could be used creatively, enabling them to resist the control exerted in their family, and retain a sense of their own capacity for agency. In the third theme, play and relationality, we explore the relational context and form of CYPs play, and particularly their descriptions of the way that their capacity for play and creativity enabled them to maintain caring relationships, and a sense of self as a caring subject.

\section{Play and coercive control}

Families where DVA occurs are typically characterised by broader relational patterns of coercion and control. Whilst coercive control is often seen as restricted to the intimate dyad, coercive dynamics pervade the relational terrain of the family. CYP we interviewed noted that controlling their play was one way in which coercive control was exerted in the family. For example, Ali (England, 14) says:

\footnotetext{
Yeah and then if me and Tina are playing, he gets all angry and throw, like, yesterday he threw a Lego across the room cos he went angry just because me and Tina were mucking about ...We're only kids we're allowed to play, and he don't fucking understand that? It's very annoying.
}

Ali represents the abusive parent as irrationally disrupting their ordinary play interactions. Many of the children we interviewed described how they would not play in communal areas of the house, talked about 'walking on eggshells' round their abusive parent, and playing quietly to avoid drawing their attention to them. In this sense it is clear that child play is an area violent adults might use to extend their control through the family. 
However, in this extract, Ali also uses her description of play to implicitly problematize her father's controlling behaviour. Play is described as normal and natural to children, and this construction enables Ali to position his behaviour as inappropriate. Her father uses his anger to restrict the relational space, blocking their ability to play freely, and expresses his anger with their toys, reinforcing a sense of prohibition to normal childhood play. Without explicitly labelling him, Ali's naturalisation of child play, and phrases like 'allowed to play', and 'he don't fucking understand that' enable her to position him as a problem parent, an unnatural father, disrupting her normal childhood. She has not had to name him as bad father, or directly called his behaviour abusive, as this would breach family taboos around talking about DVA (Callaghan, Alexander, Mavrou, et al., 2016). However, she is able to deploy notions of 'normal' childhood and parenting to identify the controlling dynamics she has experienced.

CYP also used play as a gesture of resistance and defiance (Hebdige, 1979; Callaghan and Clark, 2007; Callaghan, Alexander, Sixsmith, et al., 2016), seeing the potential play offered to relieve them, temporarily from the limitations that violence, control and constraint imposed on them at home (Callaghan and Alexander, 2015). In this example, Christina (Greece, 12) is asked how she coped with violence at home:

Christina: Me? I'd leave...

Int: You'd leave? Where would you go?

Christina: I'd go to play, to sit. We had, my friends, my friends and I had built a secret place, a den... We'd go to a river and throw stones over there.... And we'd go there, and we'd swim.

Christina sees her play with her friends as a form of coping, a means of escape. She describes their construction of a 'secret place', a 'den'. This construction of a 'secret' children's world, combined with the bucolic images of the river and stone throwing suggests a safe children's space, separate 
from the violent spaces of the home, that offers Christina a sense of freedom, and of free play. It recalls the possibility of a 'normal' childhood. The 'secret' nature of this world, shared only by her and her friends positions it as safe from the potential intrusion of adults. In that sense it produces a potential for resistance to the control and constrain that her violent father imposes on her.

Similarly, Lina (Greece, 15 ) talked about escaping to her friend Rika's house - a house that was peaceful and free of violence:

My best friend, Rika, lived across the street ... so, I could go somewhere where it would definitely be quiet ((.)) because her family didn't cause troubles and stuff... we were sitting and watching tv, we would mess up the whole house and then re-tidy it... we did each other's hair ((eeh)) we were doing our make-up, taking off make-up, we did silly things.

Lina describes her friend's house as a place of escape. She describes it as ordinary and everyday - a place where she can play and "do silly things" that she cannot do at home. Like Christina, she copes with the situation at home by finding a safe space where she can be herself, and can go on being a child, free to play with her friend.

This sense of the value of free play and social interaction away from the adult world is echoed by Emma (England, 14) who notes that because of the violence and control at home, she felt that she missed out on the experience of being a child.

Emma: Yeah, I mean, the way I feel now is, I felt like, ((erm)), what's the word ((.)) I didn't really have a childhood.... Because like I had to grow up so quickly, that I didn't really have a childhood, like, ((erm)), I didn't really have like them, ((erm)), times where you get to play with people your own age, that kind of thing, just didn't have that really, I didn't really go out. 
Her understanding of childhood is rooted in access to free play, and a sense of being able to play with other children away from adults. In the context of this sense of a lost childhood, her school based friendship is seen as particularly important:

Emma: She just made me forget things really, like, so it would be just me and her at like break times and lunch times and we'd, I don't know, we'd do things like hopscotch and skipping ropes and football, that kind of thing, at the back of the playground where no one really went, because they were all on the field-

Int: -Yeah.-

Emma: Summer time, so we'd all be on the concrete right at the back of the building and no one could annoy us ((laughs)).

The social nature of this interaction is important - underscored by the use of the term 'we', emphasising the shared nature of this interaction. Lizzy's account of play centred on a shared experience of violence with her friend Kim, and their ability to construct a friendship that is both founded on that shared experience, and untroubled by it.

Lizzy: Yeah. And me and my friend Kim we used to have giant rocking horses, I used to take 'em into her garden, ((laughs)) oh it was really hard to get them over the fence, but we took 'em in the garden and we used to play cowboys, and ((laughs)) yeah, that was fun.... Yeah, yeah. So we, we were both, like, were in the same situation 'cause like, yeah, it was better for us to speak about it. We didn't really speak about it though, to think about it. Yeah. We've said a few things, like what's been happening, and then we'd just go straight into playing or doing something else.

In this relational context, play also functions as a space to assert a sense of self. For instance, in the extract below, Peter (England, 8) is interviewed in a play room, which includes some toys that are very loud. As he plays with one of these noisy toys, he shouts out: 
Peter: ((Playing loudly)) It's good to be me!

Int: Good to be you. ((laughter)) It's nice to be able to express yourself. Have there been times when it's been hard to just be you, to express yourself?

Peter: Yeah. I got noisier.

In his interaction with the interviewer, Peter both enacts and describes a key coping strategy he has developed to cope with the controlling and abusive dynamics of home. In his play, he revels in himself - 'it is good to be me', enjoying who he is and how loud he can be. Play becomes a form of self-assertion and explicit resistance, being noisy when DVA more typically demands silence.

Play re-makes the world

DVA disrupts children's home and leisure spaces, rendering them as risky and over-regulated. Because of its creative and fantasy nature, play offers children a resource with which they can 'remake' their world, resisting the colonisation of their material world as a site of oppression and control. Play opens a space in which the child can be absorbed, becoming lost temporarily to their 'real world' of adult violence and coercion. As Andy (England, 12) and Kostas (Greece, 14) note:

Andy: Because if I'm playing a game it just - I don't think about anything I just think about the game.

Kostas: My mind was let's say on the game. I was playing. I was playing and it wasn't on my mind at all, I was just playing. I would forget about this chaos that was going on... To think, but not about that thing... I think about something else, for example ((.)) 'Pass me the ball, do', you're in the game, you don't ((.)) (INSERT FIG 3 about here)

Play can be all-absorbing, drawing them into a child-centred space in which they have a stronger sense of control. In these extracts, games offer spaces in which they can think, but that their 
thoughts are not resting on their family difficulties. Kostas in particular highlights the intersubjective nature of this strategy - he can lose himself in his interactions with other children, where their demands on his attention require that he retains a focus on the present, and not be preoccupied with the familial conflict.

That sense of control is particularly notable in the account of two brothers, George and Paul, whose father had been involved in car-crime. They were particularly fond of playing 'Grand Theft Auto', an Xbox game that enabled them to be entirely absorbed in an imaginary world. Whilst this was not a violence free space, it was a space in which chaos and violence was under their control:

Paul: We've got our own, we've got our own....

George: and if someone kills you, it tells you what they've done to you!

Paul: Oh yeah, like when you die.... My friend was on the Xbox live .... And then his friend shot my friend....

George: And because it's a game, you can just shoot them. Or you can go and drive around and go on a rumble. When Paul gets angry, he can go and play on Grand Theft Auto. He can go on the Xbox and he has all these cars and he has like the FBI chasing him, and military cars, like chunky cars he can drive around.

Int: OK, so if you had someone who was in a really difficult situation like that, would your advice be to find a way of like getting your anger out? Like you have?

George: Yeah. Yeah.

Int: Sounds like as well like you can get away from things, when you're on your Xbox.

George: It's like having a world of your own. A world of your own. Cause like, when you've got a game, you can do what you want. 
In the virtual world of Grand Theft Auto, George and Paul are able to play 'power games' safely. Given that George and Paul's father was involved in automobile crime, and conformed strongly to a masculine identity rooted in violent machismo, the choice of game does not seem accidental. Effectively, they were enabling themselves to play safely, with them in charge, in their father's world. Violence and death become predictable, controllable phenomena, and so virtual environments function as a safe space, where issues of violence can be processed in an environment where the young person has agency and control. It is a space for pretend play in which his rage can be safely expressed, and he is able to escape authority figures in 'chunky cars'. It is a virtual space in which they can be liberated from the constraint of coercive control: they are nor victims or perpetrators.

Children were able to construct these virtual worlds for themselves even in the absence of material objects like Xboxes to support them. Fabio (Italy, 13) brought a photo of a rainy window, to illustrate his sense of how he coped with DVA. (INSERT FIGURE 1 ABOUT HERE) He said:

When it rained it was always a bad day. When the weather was good I went out with my good friends, we went around the city. Above all we went out to do graffiti. But when it rained I often stayed at home. Sometimes I passed my time by looking at the drawings made by rain drops on the window. I preferred to think about nothing. My father always stayed on the couch watching television. My mother, on the other hand, watched it in the kitchen. And when not watching television, they screamed. It was really better when they watched television. I could never watch it during the afternoon when they were there and so I looked at the window, it was like my personal TV.

In Fabio's account, the window functions as a space of potentiality, offering the possibility of escape, and of a world beyond the violent family home. He makes creative use of the limited space and the 'toys' available to him, using the window and his own imagination as a plaything, using it to break away from the physical limitations imposed by his home and the stifling hostility of the family 
environment. The rain is creative, but also calming. He thinks 'about nothing', effectively meditating on the drops of rain on the window pane. In addition to the escape offered by his fantasy, it also facilitates his ability to self-soothe in circumstances of emotional strain. Alicia (Spain, 12) also uses drawing as escape strategy; to create an imaginary world where home is a safe, warm and cozy place - she is able to use it to create a safe domestic environment, bucolic and happy:

I draw mostly little houses...houses on the top of the hill... with a smoking chimney ...and a giant smiley sun...and there are granaries...and other things...

This sense of the fantasy escapism offered by play and creativity is also described by Kostas (Greece, 14). He brought a photo of his drawing, that incorporated two Greek words "I imagine" and "I dream". (INSERT FIGURE 2 ABOUT HERE) He says:

My imagination. I think various things. For example, to be up in the mountain with my friends, running, doing, playing. There are moments where I imagine ghosts too, for example like an adventure.... Dream: It's like I'm flying. Somewhere, in another world.

Like Fabio, Kostas uses his imagination to generate a space of escape, a relational space, in which ordinary play with his friends is possible. It is a high space, imaginally located beyond the family conflict, and it also a space of action - of doing, running and playing. In his imagination, therefore, he is exceeding the constraint and limitation imposed by the controlling relational dynamics of the violent family.

We acknowledge how DVA might function as relational trauma, and appreciate the importance of understanding the impact of trauma on CYP. However, it is also important to acknowledge the risk of presuming damage, and the potential of that presumption to obscure the creativity and complexity of play. By exploring CYPs experience of play in its spatial and relational context, we have challenged representations of children as only damaged and only passive victims of DVA. This opens a space in 
which the paradoxical meanings of children's play might be recognised and understood, seeing how children are both wounded and coping, damaged and resistant.

Play and relationality

In many of the extracts we have considered so far, play is clearly a relational phenomenon - it enables children to connect both to other children and adults, and to the environment. Several children talked about play as a way of caring for others, particularly for younger siblings. For example, in the extract below, Paolo (Italy, 15) describes the way he created a sense of physical safety for him and his brother by creating a barricade across the bedroom door. However, he transforms this quite terrifying experience through the use of play:

I'd go to my room with my siblings, but we didn't have the key (to lock it). We were scared, and we'd push a couch in front of the door to block it. We'd look through the keyhole and listened to them shouting. The worst times we'd hide in the closet. We'd move the large to the door. First the couch then the closet, we wanted to lock the door. And I'd hide on the top bunk bed, where I made a kind of fortress: I put some cushions -the ones from the couch that were more firm- and I hid myself there with my siblings and we'd play with Lego, because the bed was big enough, all three of us could fit up there... I suggest creating an environment that's in your favour. Like we sometimes put blankets between the bed above and below and we went in there with an electric torch. And we'd play music....

Turning the barricade into a blanket fortress, he constructs a safe space for him and his siblings. He lights it with a torch, and uses music to close out the sound. It is striking how creative his transformation of space is, as he acts to protect his siblings both physically and emotionally; instead of allowing the erection of a physical barricade to be something terrifying, he uses pretend play and creativity to reshape it into a game. Whilst it is important to remember Paolo is recalling incidents from when he was as young as 6 , nonetheless, his narrative is compelling and powerful: 
And I was trying to be OK with my siblings. Ever since I was little I always tried ... I've got things I understood even if I was young, but still older than my siblings, and I always tried to make them understand in the form of a game, like Benigni in 'Life is beautiful'.

In "Life is Beautiful", Benigni uses storytelling and pretend to convince his son that a Nazi concentration camp in which they were interred was just a game, transforming it from a horrendous nightmare to an everyday and sometimes quite magical reality. In adopting this self-description, he takes on a relatively powerful position, as storyteller, as creator of an alternate reality, resisting the material reality in which his father exerted such extreme power and control. Play operates here as a buffer, shutting out arguments and violence, creating a children's space, in the real or fantasy world, in which the siblings are able to soothe and comfort each other.

Nancy (England, 8) illustrates children's capacity to use play to 'remake' the world. Despite an experience of isolation, she is able to conjure for herself secret playmates, who entertain and comfort her:

And when I'm at my dad's I go and sit in a tight space in a bedroom where I can just like play stuff, like sometimes I play with my fingers and pretend I'm playing a game, 'cause it just makes me feel happier, 'cause I know, it makes me feel like I'm not alone Int: What sorts of games do you play?

Nancy: I play catch me, I play football, umm I just play friends Int: What d'you mean, can you show me?

Nancy: ((Shows games she plays with her fingers)) 'Catch me' as in running around and the other one's got to get you ((gestures two fingers from each hand trying to catch each other)). 'Football' as in playing dribbling ((gestures two fingers from each hand playing football)). 'Friends' as in you're just being friendly ((brings two hands closely together and interlocks at the knuckles)). It just makes me feel like there's someone there. 
Int: and when do you do that?

Nancy: When I'm scared, when I'm angry, when I'm alone and I don't have any toys with me In the 'tight space' of a cupboard, she withdraws to soothe herself. Playing alone, she conjures up playmates, using her fingers to stand in for other children, who can play football, be friends, giving her some entertainment and solace. This enables her to resist the control of the relational spaces of the home, by imaginatively populating the space with other children, and it enables her to overcome the material deprivation of her home, by using imagination and her own body to produce an imaginal home that is safe, friendly and comforting. Coercive control and violence have the ability to 'unmake' the world for children, but child's play has the capacity to remake it again, giving them a toehold from which to hold onto a sense of agency and resistance.

\section{Discussion}

In this analysis we have explored three themes relating to CYP's play in circumstances of DVA. We have highlighted how play is simultaneously an arena of coercion and control and one of agency and resistance to that control. Through it, children are able to construct explicit resistance to experiences of coercive control in family relationships. We have explored the capacity of play to create and inhabit/seek refuge in alternative spaces: these include material, but unconventional safe spaces and imaginary or artistic/creative ones. We have also highlighted how play enables children to remake the spaces of home into contexts that feel safe and that enable children to assert agency, even as that agency is undermined through coercive dynamics. We have demonstrated the relational significance of play as a means of retaining caring and comforting sibling relationships, and as a way of maintaining a sense of connectedness even in the wake of violence that often undermines children's sense of relationship. 
In understanding the experience and function of play in the context of DVA, it is important to recognise its locatedness and its complexity. The instances of play we have described here are complex and creative, evidencing a rich potential for play to support children in retaining a sense of themselves as agents, able to act to manage their experiences of violence, and to transform their familial and home context into a more nurturing and comforting relational and physical space, in a creative, virtual or fantasy world. Mental health professionals and developmental theorists have long acknowledged the healing and cathartic potential of play - its ability to allow children "to create controllable events in an imaginary frame where negative emotions can be freely vented"(Capurso and Pazzagli, 2016, p. 40). However, our analysis suggests that children's play goes beyond emotional catharsis and self-healing. Through play, children can imaginally transform their worlds, to remake that which has been unmade through violence and coercion, and to recreate safe spaces for themselves within and beyond the violent home.

Children's play is both resistant and constructive, enabling children to express themselves, to construct safe spaces for themselves, and to retain a sense of relational connectedness. It is important to note that this creativity is not always play in a form adults might recognise - it is not 'innocent' or 'fun'. It's a performance of play, a conscious and somehow painful assertion of normative childhood in the face of abuse and control. These accounts show skilful, reflective and empathic thinking and acting to protect, distract and comfort younger siblings. CYP are able to take into consideration and prioritise physical and emotional wellbeing of themselves and their siblings and plan and act accordingly. They are aware of the extranormative nature of their childhood experiences, and use play experiences to produce a sense of childhood for themselves and for their siblings. Despite drawing on very limited resources - often only their own imagination - their use and invention of play is highly creative and offers examples of resilience and resistance. 
Whilst we have collated a large sample of participants, it was not our intention to only recruit families where the main identified victim was female, only a small number of participants came from families where the main identified victim was male, or where professionals judged both partners to be violent. This may limit the relevance of these findings to other families.

An important implication of this analysis is to emphasise the importance of play for children's wellbeing, maintenance of a sense of agency and capacity for self-expression. DVA rarely happens in isolation and is often associated with drug misuse and adult mental health issues, as well as broader socio-economic difficulties. For children who have experienced the trauma of DVA, it is important to ensure that play spaces are available - in public, in schools, and in shelters and domestic abuse services. In the current political climate, when resources for supporting children have been dramatically reduced, and many families are face very difficult economic and social circumstances, our findings strongly advocate for more dedicated services for CYP and families who experience DVA. We argue for more and diverse resources for supporting children to both have opportunities to play in the company of trained professionals and away from adults. Whilst many organisations offer interventions to support mothers and children to play more easily together, it is important to recognise that play is not just a parent/adult-and-child phenomenon. It is also important to recognise children as agents in play, enabling them to play freely in relatively unfettered contexts.

\section{Reference}

Alderson, P. and Morrow, V. (2004) Ethics, social research and consulting with children and young people. Barndardo's.

Almqvist, K. and Broberg, A. G. (1997) 'Silence and survival: Working with strategies of denial in families of traumatized pre-school children', Journal of Child Psychotherapy, 23(3), pp. 417-435. doi: 10.1080/00754179708254560. 
American Psychiatric Association (2013) Diagnostic and Statistical Manual of Mental Disorders.

Arlington: American Psychological Association. doi: 10.1176/appi.books.9780890425596.744053.

Bridger, L. (2013). Seeing and Telling Households: A Case for Photo Elicitation and Graphic Elicitation in Qualitative Research. Graduate Journal of Social Science, 10(2), 106-131.

Burman, E. (2017) Deconstructing Developmental Psychology, 3rd Edition. London: Routledge.

Callaghan, J. E. M. (2015) 'Mothers and Children? Representations of mothers in research on children's outcomes in domestic violence', Psychology of Women Section Review, (16), pp. 2-5.

Callaghan, J. E. M., Alexander, J. H., Sixsmith, J., et al. (2016) ‘Beyond "witnessing”: Children's Experiences of Coercive Control in Domestic Violence and Abuse', Journal of Interpersonal Violence.

Callaghan, J. E. M., Alexander, J. H., Mavrou, S., et al. (2016) 'The Management of Disclosure in Children's Accounts of Domestic Violence: Practices of Telling, and Not Telling', Journal of Child and Family Studies, 26(12), pp. 3370-3387. doi: 10.1007/s10826-017-0832-3.

Callaghan, J. E. M., Fellin, L. C. L. C., et al. (2017) ‘Children and domestic violence: Emotional competencies in embodied and relational contexts', Psychology of Violence, 7(3), pp. 333-342. doi: 10.1037/vio0000108.

Callaghan, J. E. M., Alexander, J. H., et al. (2017) ‘Practices of Telling, and Not Telling: The Management of Disclosure in Children's Accounts of Domestic Violence', Journal of Child and Family Studies. Springer US. doi: 10.1007/s10826-017-0832-3.

Callaghan, J. E. M. and Alexander, J. H. (2015) Understanding Agency and Resistance Strategies: Children's Experiences of Domestic Violence Report. Northampton. Available at: www.unars.co.uk.

Callaghan, J. E. M., Alexander, J. H. and Fellin, L. C. (2016) 'Children's embodied experiences of living with domestic violence: "I'd go into my panic, and shake, really bad"', Subjectivity. Palgrave Macmillan UK, 9(4), pp. 399-419. doi: 10.1057/s41286-016-0011-9. 
Callaghan, J. E. M. and Clark, J. (2007) 'Feminist Theory and Conflict', in Ratele, K. (ed.) Intergroup Relations: A South African Perspective. Cape Town: Juta.

Capurso, M. and Pazzagli, C. (2016) 'Children's Health Care Play as a coping strategy?: A review of the relevant literature literature', Children's Health Care. Taylor \& Francis, 45(1), pp. 39-66..

Chazan, S. and Cohen, E. (2010) 'Adaptive and defensive strategies in post-traumatic play of young children exposed to violent attacks', Journal of Child Psychotherapy, 36(2), pp. 133-151. doi: 10.1080/0075417X.2010.495024.

Cohen, E. et al. (2010) 'Posttraumatic play in young children exposed to terrorism: An empirical study.', Infant mental health journal, 31(2), pp. 159-181. doi: 10.1002/imhj.

Denzin, N. K. (2001) Interpretive Interactionism. Newbury Park: Sage.

Eriksson, M. and Näsman, E. (2012) 'Interviews with Children Exposed to Violence', Children \& Society, 26(1), pp. 63-73. doi: 10.1111/j.1099-0860.2010.00322.x.

Fearn, M. and Howard, J. (2012) ‘Play as a Resource for Children Facing Adversity : An Exploration of Indicative Case Studies', Children \& Society, 26, pp. 456-468. doi: 10.1111/j.10990860.2011.00357.x.

Friedman, M. J. (2014) 'Literature on DSM-5 and ICD-11', PTSD Research Quarterly, 25(2), pp. 1-10. doi: 10.1016/j.yhbeh.2015.04.002.

Georgsson, A., Almqvist, K. and Broberg, A. G. (2011) 'Naming the Unmentionable: How Children Exposed to Intimate Partner Violence Articulate Their Experiences', Journal of Family Violence, 26(2), pp. 117-129. doi: 10.1007/s10896-010-9349-x.

Gil, E. (2013) Working with Children to Heal Interpersonal Trauma: The Power of Play. New York: Guilford Press.

Gil, E. (2017) Posttraumatic Play in Children: What Clinicians Need to Know. New York: Guilford Press 
Glodich, A. and Allen, J. G. (1998) 'Adolescents Exposed to Violence and Abuse : A Review of the Group Therapy Literature with an Emphasis on Preventing Trauma Reenactment', Journal of Child and Adolescent Group Therapy, 8(3), pp. 135-154.

Goodyear-Brown, P. (2009) Play therapy with traumatized children. Hoboken: John Wiley \& Sons. Hebdige, D. (1979) Subculture: The Meaning of Style. London: Accents.

James, A., Jenks, C. and Prout, A. (1998) Theorizing Childhood. Willeston: Teachers College Press. James, A. and Prout, A. (2015) Constructing and Reconstructing Childhood: Contemporary issues in the sociological study of childhood. London: Routledge.

Katz, E. (2015) ‘Domestic Violence, Children’s Agency and Mother-Child Relationships: Towards a More Advanced Model', Children \& Society, 29(1), pp. 69-79. doi: 10.1111/chso.12023.

Katz, E. (2016) 'Beyond the Physical Incident Model : How Children Living with Domestic Violence are Harmed By and Resist Regimes of Coercive Control', Child Abuse Review, 25(November), pp. 46-59. doi: $10.1002 /$ car.

Keren, M. et al. (2005) 'Relations between parents' interactive style in dyadic and triadic play and toddlers' symbolic capacity', American Journal of Orthopsychiatry, 75(4), pp. 599-607.

Lubit, R. et al. (2002) 'Forensic evaluation of trauma syndromes in children', Child and Adolescent Psychiatric Clinics of North America, 11(4), pp. 823-857. doi: 10.1016/S1056-4993(02)00026-3.

Marshall, D. J. (2016) 'Existence as Resistance: Children and Politics of Play in Palestine', in Kallio, K., Mills, S., and Skelton, T. (eds) Geographies of Children and Young People. Singapore: Springer, pp. 245-262. doi: 10.1007/978-981-4585-57-6.

Morris, A., Hegarty, K. and Humphreys, C. (2012) 'Ethical and safe: Research with children about domestic violence', Research Ethics, 8(2), pp. 125-139. doi: 10.1177/1747016112445420.

Överlien, C. (2017) “'Do you want to do some arm wrestling?”: children's strategies when 
experiencing domestic violence and the meaning of age', Child and Family Social Work, 22(2), pp. 680-688. doi: 10.1111/cfs.12283.

Punch, S. (2000) 'Children's Strategies for Creating Play Spaces: Negotiating independene in rural Bolivia', in Holloway, S. L. and Valentine, G. (eds) Children's Geographies: Playing, Living, Learning and Transforming Everyday Worlds. London: Routledge, pp. 48-62.

Sachser, C. and Goldbeck, L. (2016) 'Consequences of the Diagnostic Criteria Proposed for the ICD-11 on the Prevalence of PTSD in Children and Adolescents', Journal of traumatic stress, 29(2), pp. 120123. doi: $10.1002 /$ jts.

Scarry, E. (1985) The Body in Pain. Oxford: OUP.

Schaefer, C. and Drewes, A. (2013) The Therapeutic Powers of Play: 20 Core Agents of Change. (Second Edition). Hoboken: John Wiley \& Sons.

Scheeringa, M. S. et al. (2012) 'Diagnosing PTSD in early childhood: an empirical assessment of four approaches', Journal of Traumatic Stres, 25(4), pp. 359-367.

Skansvors, L. (2009) 'Ethics in Child Research: Children's Agency and Researchers' “Ethical Radar"', Childhoods Today, 3(1), pp. 1-22.

Skelton, T. (2009) 'Children 's Geographies / Geographies of Children : Play, Work, Mobilities and Migration', Geography Compass, 3/4, pp. 1430-1448.

Smith, D. E. (2005) Texts, Facts and Femininity: Exploring the relations of ruling. London and New York: Routledge, Taylor \& Francis.

Sossin, K. M. and Cohen, P. (2011) 'Children's Play in the Wake of Loss and Trauma', Journal of Infant, Child, and Adolescent Psychotherapy, 10(2-3), pp. 255-272. doi: 10.1080/15289168.2011.600137.

Stark, E. (2007) Coercive Control: How Men Entrap Women in Personal Life. New York: Oxford 
University Press.

Tedeschi, F. K. and Billick, S. B. (2017) ‘Pediatric PTSD: Clinical, forensic, and diagnostic understanding.', Journal of the American Academy of Psychiatry and the Law, 45(2), pp. 161-169. Available at:

http://ovidsp.ovid.com/ovidweb.cgi?T=JS\&PAGE=reference\&D=psyc13\&NEWS=N\&AN=2017-36853003.

Terr, L. (1981) “Forbidden Games": Post-Traumatic Child's Play, Journal of the American Academy of Child Psychiatry, 20(4), pp. 741-760.

Thompson, L., Rickett, B. and Day, K. (2018) 'Feminist Relational Discourse Analysis: putting the personal in the political in feminist research', Qualitative Research in Psychology. Routledge, 15(1), pp. 93-115. doi: 10.1080/14780887.2017.1393586.

Tomkin, A. (2014) Play in Healthcare. Routled. London.

Valentino, K. et al. (2006) 'Mother - Child Play and Emerging Social Behaviors Among Infants From Maltreating Families', Developmental Psychology, 42(3), pp. 474-485. doi: 10.1037/00121649.42.3.474.

Vetere, A. and Cooper, J. (2017) 'Children who witness violence at home', in Vetere, A. and Dowling, E. (eds) Narrative Therapies with Children and their Families: A Practitioner's Guide to Concepts and Approaches. 2nd edn. London: Routledge.

Wood, S. L. and Sommers, M. S. (2011) 'Consequences of intimate partner violence on child witnesses: a systematic review of the literature.', Journal of child and adolescent psychiatric nursing : official publication of the Association of Child and Adolescent Psychiatric Nurses, Inc, 24(4), pp. 22336. doi: 10.1111/j.1744-6171.2011.00302.x. 